\title{
IMPROVING RISK ADJUSTMENT IN THE CZECH REPUBLIC
}

\author{
Radovan Chalupka*
}

\begin{abstract}
:
This paper analyses possible options how to improve the risk adjustment of the health insurance system in the Czech Republic. From the possible options it argues for including pharmaceutical cost groups (PCGs) as additional risk factors since it is an improvement that can be implemented almost instantaneously. On real data from an anonymous sickness fund it confirms that predictive performance of PCGs models is consistently better than the performance of the demographic model that is currently used. The study also describes and examines the Czech health insurance market and implications of proposed changes of policy makers. Based on experience from other countries we point to a problem of risk selection if the changes are not accompanied by a tighter regulation, specifically in the form of improved risk adjustment formula.
\end{abstract}

Keywords: risk adjustment, health insurance, pharmaceutical cost groups, Czech Republic

JEL classification: C10, D82, G22, I10, I11, I18

\section{Introduction}

Health care policy is currently one of the key economic and political issues in Europe and the United States. Health care systems face challenges of population ageing, new medical technologies and higher expectations of health care services by consumers, which increase demand for financial resources. Increasing health care production efficiency is a natural response to these challenges; however, attaining higher efficiency is made more difficult by a concurrent demand for equal access to health care. Compared to majority of other goods, equity in consumption of health care services is considered to be more important, which makes functioning of health care markets more difficult.

One of the possibilities aimed to achieve adequate level of efficiency and equity envisioned by Enthoven (1988) is managed competition ${ }^{1}$ with a role of insurers paying for health care consumed by insured individuals. Acting as agents, the insurers collect funds and buy health care for their customers. Competition between the insurers ensures better consumer choice whereas financial accountability provides incentives to minimise costs of covered health care services. This should ultimately result in increased production efficiency of a health care system, taking into account both

* Radovan Chalupka, IES, Faculty of Social Sciences, Charles University in Prague, Opletalova 26, CZ - 110 00, Prague 1 (chalupka@fsv.cuni.cz)

1 The term managed implies a need of appropriate regulation of a health care market as described later in the paper. For a more recent update of this concept the reader is referred to Enthoven (1993) or Enthoven (2007). 
production level and costs. Equity (or solidarity ${ }^{2}$ ) within the framework of competing insurers can be achieved by a system of risk adjustment. ${ }^{3}$ Under a system of risk adjustment, premiums ${ }^{4}$ to be received by an insurer are adjusted for a risk of each insured individual based on characteristics, such as age, gender or health status. All or part of health insurance contributions collected by all insurers are pooled together and then redistributed; insurers insuring people with higher expected ${ }^{5}$ health care costs receive higher premiums and vice versa. This mechanism supervised by a sponsor, such as government, enables cross-subsidisation between individuals (groups) with lower and higher risk. ${ }^{6}$ Van de Ven (2000) summarises this concept by defining risk adjustment as "the use of information to calculate the expected health expenditures of individual consumers over a fixed interval of time (e.g., a month, quarter, or year) and set subsidies to consumers or health plans to improve efficiency and equity".

The systems of risk adjustment used worldwide are currently not perfect (van de Ven, 2000). They are able to capture only a proportion of variation in health care expenditures. Moreover, the insurers providing basic health insurance are typically restricted to set insurance premiums, ${ }^{7}$ which provides incentives to select profitable individuals with lower expected costs than the compensation received by the insurer and distract those with expected losses. This process of risk selection (also being called cream skimming or cherry picking) undermines the benefits of competition between the insurers who are not competing in their ability to buy the best health care services but in their ability to select the most advantageous risks (the resources used in this process being a welfare loss - van de Ven, 2003). The risk selection can take various forms, from the most visible forms such as refusing selected potential enrolees $^{8}$ to more subtle ways such as selective marketing or providing lower quality

2 Van de Ven (2003) defines two types of solidarity; risk solidarity entails that individuals with low risk (healthy persons) subsidise those with higher health risks while income solidarity implies redistribution between individuals with higher income who pay higher insurance contributions to subsidise individuals with lower income. A combination of both enables general accessibility of health care to members of a particular community (e.g. a country).

3 Other terms for risk adjustment with similar meaning, such as risk compensation or risk equalisation are used in the literature. In the Czech Republic the concept of risk adjustment is being referred to as redistribution of insurance premium income. For an excellent discussion of risk adjustment terminology the reader is referred to Ellis (2008).

4 Three different expressions are encountered in the literature - risk adjusted premiums, risk adjusted payments or risk adjusted capitation.

5 From the efficiency perspective, it is preferable to base risk adjustment on expected costs (prospective risk adjustment), however, full or partial retrospective risk adjustment based on actual costs is also encountered.

6 There are also cross-subsidies from people with higher income to people with lower income (income solidarity) as insurance premium contributions are typically at least partly calculated as a fixed percentage of income.

7 In the Czech Republic insurers have no discretion to set insurance premium as it is set by the legislation.

8 Refusing of potential enrolees is usually made officially impossible by law for mandatory basic insurance (open enrolment requirement). However, if supplemental voluntary insurance (no open enrolment requirement) is sold together with the basic insurance, insurers who refuse to provide supplemental insurance to unfavourable risks can possibly distract them also from buying the basic insurance (van de Ven, 2007). 
care for the unprofitable risks (e.g. chronic patients), thus forcing them to change the fund.

The contributions of this paper are the analysis of possible options to improve the risk adjustment system in the Czech Republic and health care policy recommendations based on the lessons from other countries documented in the literature.

Currently only age/gender risk factors are used and hence naturally there is a room for improvement. We analyse various alternatives from the literature and choose an improvement based on Pharmaceutical Cost Groups (PCGs). The conclusion to choose PCGs is based on the fact that they can be implemented almost instantaneously. Based on a sample of real data we confirm that adding PCGs significantly improves predictability of health care expenditures.

In the next section we provide a description of the current risk adjustment system in the Czech Republic followed by quantitative analysis on real Czech data in the third section. Our main finding is that employing PCGs significantly more variance is explained, the part of resources redistributed due to pharmaceutical groups is quantitatively important and hence risk selection incentives are lowered. In the fourth section, we discuss important policy issues regarding risk adjustment and risk selection and draw conclusions relevant for the Czech Republic. We conclude all the findings in the final fifth section.

\section{Risk Adjustment and Risk Selection in the CR}

\subsection{Risk Adjustment in the Czech Republic}

In the Czech Republic, a system of health insurance in health care delivery was implemented in 1993. There are significant differences between the sickness funds both in the average income level of the enrolees as well as their morbidity. Therefore, insurers having disproportionally higher number of employees in their enrolee structure compared to the total population receive higher income (payment of the state for economically non-active insured has been significantly lower than the average payment from the income) and have to pay lower amount for health care (enrolees are healthier). These two inequalities used to be solved by a quite simple system of risk adjustment. A fraction (50\% and then $60 \%$ ) of the total income collected by all insurance funds plus the payments of the state was redistributed to the insurers according to the total number of enrolees for whom the state was the payer; differentiating between the people under the age of 60 (weight one) and above (weight 2 and then 3 - Figure 1). This system attempted to solve both the income and morbidity discrepancy but managed to reduce only a part of the differences between the insurers. As it can be seen in the figure, age groups younger than 45 and older than 60 received higher amount of funds per enrolee than are the actual average costs while for the rests the opposite held which created incentives to attract the former and distract the latter. As a result a significant risk selection occurred and sickness funds with sicker enrolees faced profound financial problems. 
Figure 1

Actual vs. Predicted Costs Using Risk Adjustment Used in the Czech Republic until 2005

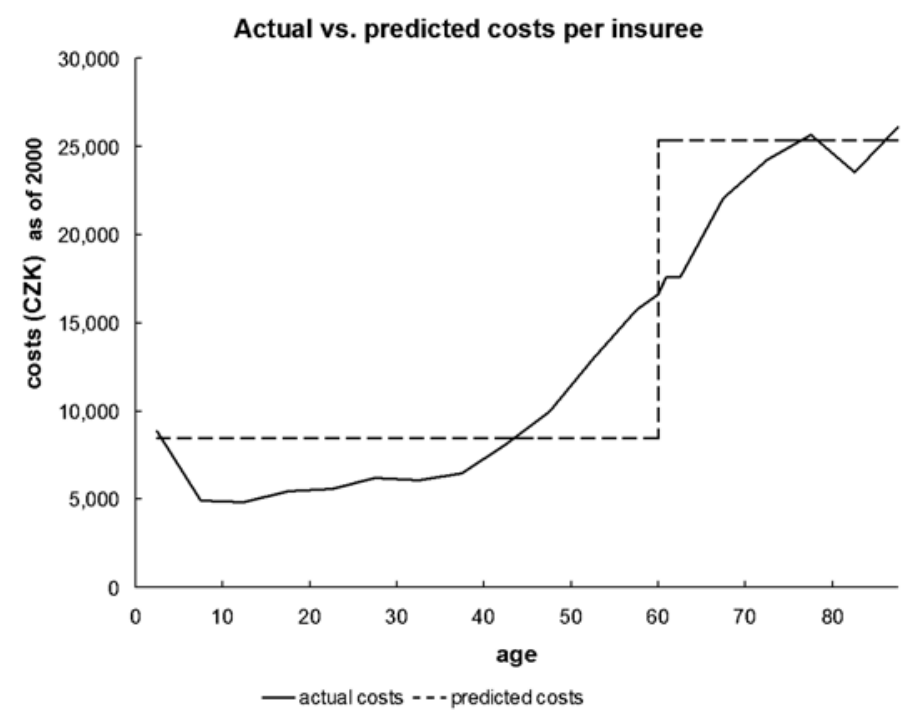

Source: Hroboň, 2007.

The first step toward a better risk adjustment system was taken in 2005 when risk adjustment according to gender and age groups was implemented. ${ }^{9}$ The entire insurance premium collected ${ }^{10}$ from enrolees and the amount from the state is now redistributed based on 18 age indices for men and the same for women (Figure 2). This eliminates the predictable losses for a given age group if a sickness fund has members with average morbidity.

Nonetheless, there is additional variability within each of 36 age and gender groups that is not explained by the demographic model. For instance, a sickness fund with a high proportion of chronically sick enrolees is worse off compared to an insurer with relatively healthy enrolees even if a different demographic profile is accounted for. The natural suggestion for improvement is to include a measure of health status in the risk adjustment formula.

Clark (1995) use information about prescribed drugs to assume chronic conditions that are correlated with higher future costs. Lamers (2004) built on this classification and adjusted it to the Dutch situation. Twenty two chronic conditions (Pharmaceutical Costs Groups - PCGs) are identified based on relevant prescription of a particular ATC group. The setback of this method is that it provides incentives to prescribe unnecessary pharmaceuticals since additional compensation may be much higher than the costs of

9 Moreover, a risk-sharing mechanism was introduced establishing a special fund for extremely costly care. Sickness funds receive ex-post compensation for $80 \%$ of costs for enrolees whose costs exceed a threshold of thirty times the average costs per an insured -i.e. a combination of outlier and proportional risk sharing (Decree No. 644/2004 Coll.).

10 I.e. $100 \%$ compared to $50 \%(60 \%)$ in the previous system. During $01 / 2005-03 / 2006$ a combination of old and the new system was effective. 
drugs themselves, Lamers (1998).11 We argue that PCGs might be a feasible option of improving the risk adjustment system also in the Czech Republic as consumption of pharmaceuticals for individuals is readily available

Figure 2

Cost Indices for Age/Gender Groups Used in the Czech Republic for the Year 2010

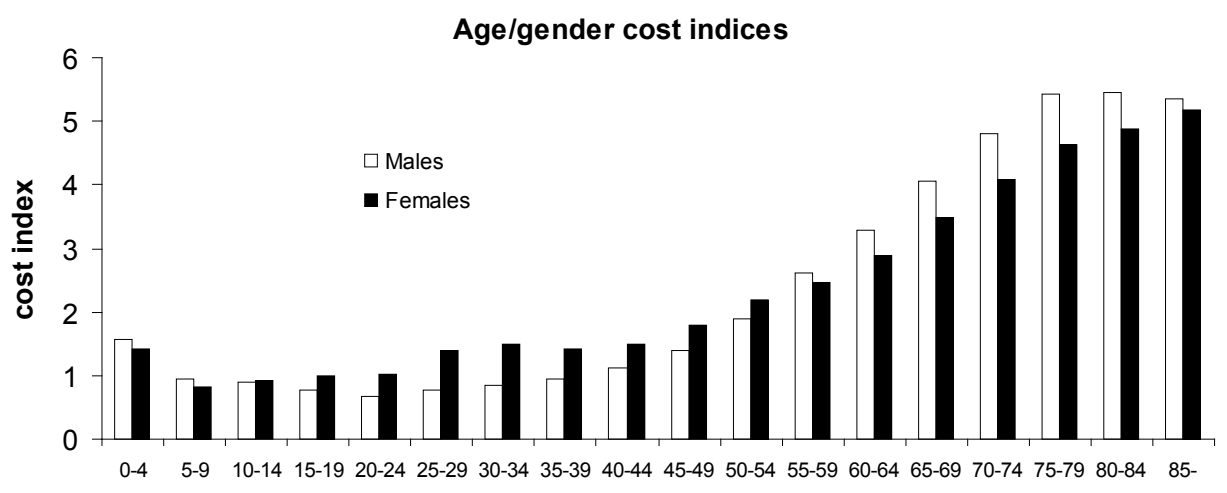

age group

Source: Decree No. 391/2009 Coll.

\subsection{Risk Selection in the Czech Republic}

Since the introduction of the new risk adjustment system in 2005, there have been no obvious signs of risk selection. However, based on our analysis of data from smaller sickness funds we have found at least two signs of risk selection of a more subtle kind. Firstly, standardised mortality in one sickness fund in certain years was very low compared to the national average. As end-life costs are both significant and might be predictable for people already in bad health, this fact indicates that the sickness fund was able to get rid of the insured persons who would represent a high loss. Secondly, our analysis of another sickness fund revealed a dramatic decrease in consumption (measured by total defined daily doses) of drug groups for people having renal problems between two years to a disproportionally low level. This again indicates motivation to "shift away" high-cost patients uncompensated by the risk adjustment system.

We can make a conclusion that although there are some signs of risk selection in the Czech Republic at the moment, the problem is not so evident. However, we believe that this a result of lack of motivation of current sickness funds to earn extra money. As they have no owners, the extra profit translates into higher reserves or pressure of doctor trade union representatives to increase reimbursement to health care

11 This disadvantage can be mitigated as argued by Lamers (2003) by the following strategies (1) requiring high number of daily doses prescribed to a patient to be included to a PCG, (2) assign each person only into one condition, and (3) exclude conditions with relatively small contribution to costs. However, based on experience from the Netherlands, the risks proved to be less pronounced and the strategies (2) and partly (3) have been abandoned since 2006 and 2007 when more PCGs were added and more than one PCG for a patient was allowed, respectively (e.g. van Vliet, 2007). 
providers. ${ }^{12}$ Entrance of private players naturally increases the motivation to earn extra profit. Therefore, we argue that the current trends in the health care market should be accompanied by tighter regulation to avoid risk selection. A better risk adjustment system is one of the steps to be taken.

\section{Empirical Analysis of PCGs in the Czech Context}

As we argued in the previous sections, utilising information from prescribed pharmaceuticals is a viable option to enhance the risk adjustment in the Czech Republic. In this section we would like to test this hypothesis using real data.

\subsection{Data and Methodology}

For the empirical part of our study, we used a sample of data about prescription drugs and total health care expenditures from an anonymous Czech sickness fund for the period 2000-2004. The data set contains initially almost 60,000 insured, this number decreases to slightly more than 50,000 as people die or leave for another sickness funds. Although relatively small, we believe this sample is able to capture typical patterns occurring in the whole system. Furthermore, the time-series of five years enables to track these patterns in time. The comparison of the data sample with the distribution of age/gender groups in the Czech Republic is presented in Figure 3.

Figure 3

Age/Gender Distribution of the Sample Data and the Czech Republic in 2004

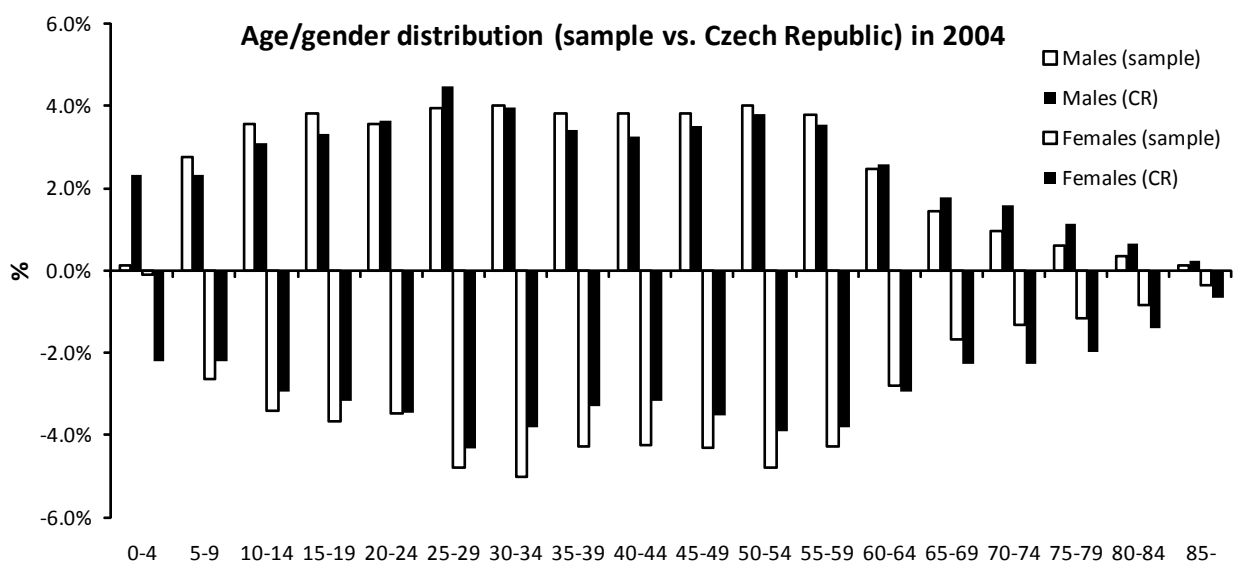

age group

Source: ÚZIS, 2004.

Health care costs data are typically extremely skewed toward the high end of the distribution. Therefore, treating many observations that are very far from a median as outliers is not appropriate. However, in each of the years 2000, 2001 and 2004 based on graphical inspection we identified a single observation that was significantly higher

12 The managers of sickness funds are yet careful to avoid losses as they would create pressure for their replacement by the representatives of the Ministry of Health Care in the governing boards. 
than even other extremely costly cases. We decided to exclude these three observations from our analysis.

To assign enrolees into a chronic condition we have essentially used the Dutch classification (Lamers, 2004) with a few exceptions; we changed the definition of low and high hypertension in a way that in our view better correspond to the current practice (Table 1), we excluded tuberculosis as it is no longer a chronic condition that cannot be cured, we excluded renal diseases due to very few individuals classified in this PCG and finally, we excluded gout because of a very small contribution to health care expenditures. ${ }^{13}$

Table 1

Definition of Hypertension Used in Our Analysis

\begin{tabular}{|c|c|c|}
\hline & ATC code & Description of ATC code \\
\hline \multirow[t]{5}{*}{ Group A } & C03A & $\begin{array}{l}\text { Low-ceiling diuretics, } \\
\text { thiazides }\end{array}$ \\
\hline & C03EA01 & $\begin{array}{l}\text { Hydrochlorothiazide and } \\
\text { potassium-sparing agents }\end{array}$ \\
\hline & $\mathrm{C} 07$ & Beta blocking agents \\
\hline & C09A & Ace inhibitors, plain \\
\hline & $\mathrm{C08}$ & Calcium channel blockers \\
\hline \multirow[t]{4}{*}{ Group B } & C09B & Ace inhibitors, combinations \\
\hline & C09C & $\begin{array}{l}\text { Angiotensin II antagonists, } \\
\text { plain }\end{array}$ \\
\hline & C09D & $\begin{array}{l}\text { Angiotensin II antagonists, } \\
\text { combinations }\end{array}$ \\
\hline & $\mathrm{C} 02$ & Antihypertensives \\
\hline Hypertension-low & \multicolumn{2}{|c|}{$\begin{array}{l}\text { At least } 6 \text { prescriptions of a drug of a single ATC code or a } \\
\text { combination of maximum two ATC codes (both must be from } \\
\text { Group A). }\end{array}$} \\
\hline Hypertension-high & \multicolumn{2}{|c|}{$\begin{array}{l}\text { At least } 6 \text { prescriptions of drugs from any group; not classified } \\
\text { as hypertension-low. }\end{array}$} \\
\hline
\end{tabular}

Additionally, our classification uses a different number of prescriptions, not 4 prescriptions as it was in the Dutch case. The numbers are quite arbitral, we tried to achieve prevalence of these conditions comparable to the original article. The list of 19 chronic conditions used in our analysis, the minimal number of prescriptions for a classification into a condition and prevalence in our dataset is shown in Table 2. It can be seen from the table that as the sample ages from 2001-2004 ${ }^{14}$, the prevalence of chronic conditions generally increases and the number of those without any condition decreases from $89.6 \%$ to $86.2 \%$.

13 The author thanks Tomáš Macháček from Health Reform Forum cz (www.healthreform.cz) and Advance Healthcare Management Institute (www.advanceinstitute.cz) who designed this PCG classification for the permission to use it for this research.

14 As we already stated, no new individuals are entering the sample. 
Table 2

List and Prevalence of Chronic Conditions in Our Dataset

\begin{tabular}{|c|c|c|c|c|c|c|}
\hline \multicolumn{2}{|r|}{ Chronic condition } & \multirow{3}{*}{\begin{tabular}{|c|}
$\begin{array}{c}\text { Min. number of } \\
\text { prescriptions }\end{array}$ \\
- \\
\end{tabular}} & \multicolumn{4}{|c|}{ Prevalence per 1,000 enrolees } \\
\hline & & & 2001 & 2002 & 2003 & 2004 \\
\hline 0 & No PCG & & 895.8 & 880.5 & 868.8 & 861.7 \\
\hline 1 & Hypertension - low & 6 & 26.7 & 31.6 & 34.7 & 36.7 \\
\hline 2 & Hypertension - high & 6 & 7.4 & 8.3 & 7.4 & 9.8 \\
\hline 3 & Glaucoma & 6 & 1.5 & 1.8 & 2.2 & 2.1 \\
\hline 4 & Depression & 5 & 4.4 & 5.0 & 6.4 & 7.7 \\
\hline 5 & Thyroid disorders & 4 & 1.8 & 2.3 & 3.5 & 3.9 \\
\hline 6 & Hyperlipidemia & 6 & 6.9 & 8.1 & 9.6 & 6.2 \\
\hline 7 & Respiratory illness, asthma & 4 & 10.7 & 15.8 & 12.9 & 13.7 \\
\hline 8 & Epilepsy & 5 & 4.1 & 4.4 & 5.1 & 4.8 \\
\hline 9 & Peptic acid disease & 5 & 9.7 & 9.9 & 10.4 & 11.9 \\
\hline 10 & Crohn's and ulcerative colitis & 3 & 0.9 & 1.1 & 1.2 & 1.1 \\
\hline 11 & Rheumatologic conditions & 4 & 1.1 & 0.9 & 0.9 & 1.1 \\
\hline 12 & Parkinson's disease & 5 & 0.9 & 0.9 & 0.7 & 0.9 \\
\hline 13 & Diabetes-type I & 4 & 5.2 & 5.7 & 5.9 & 6.2 \\
\hline 14 & Diabetes-type II & 5 & 3.2 & 6.1 & 6.6 & 4.7 \\
\hline 15 & Cystic fibrosis & 8 & 0.2 & 0.8 & 0.8 & 1.2 \\
\hline 16 & Transplantations & 3 & 0.5 & 0.7 & 0.7 & 0.7 \\
\hline 17 & Malignancies & 6 & 0.1 & 0.2 & 0.1 & 0.3 \\
\hline 18 & HIVIAIDS & 2 & 0.1 & 0.1 & 0.1 & 0.1 \\
\hline 19 & Cardiac disease/ASCVD/CHF & 4 & 18.5 & 15.8 & 21.8 & 25.1 \\
\hline
\end{tabular}

Only those insured who are present in the sample for the whole year $t$ and at least a month in $t+l$ are classified into a PCG category for a given year and included in the calculation. Based on a classification into a PCG group in time $t$, an age/gender group in $t+1$, annualised expenditures ${ }^{15}$ in $t+1$ are estimated using a linear model with intercept by ordinary least squares. Each observation is weighted with a weight equal to the number of months each person is present in the sample in period $t+1$. To obtain robust estimate of variance a Huber/White estimation of variance-covariance matrix is employed.

Predictive performance is compared by adjusted $R^{2}$ and prediction ratios. To calculate prediction ratios, the insured are ordered by their annual expenditures into ten deciles and a ratio of actual over predicted expenditures is calculated for each of these groups. Three models were utilised each year, a demographic model with 36 age/gender groups as a benchmark, PCG model allowing for co-morbidity (more than one PCG for an individual is possible $)^{16}$ and PCG model with all 19 PCGs and no

15 If a person is in the sample for 6 months in the period $t+1$, the annualised expenditures are twice the actual ones.

16 Not included in the results, yielded similar performance to the other PCG model. 
co-morbidity (54 dummy variables). To assign every enrolee to at most one PCG, the iteration procedure to rank PCGs according to decreasing costs was used as described in Lamers (2003).

\subsection{Overall Results}

The overall results are depicted in Table 3. Demographic model alone is able to explain $3.2-4.4 \%$ of the variation of expenditures. This figure increases to $8.5 \%-9.5 \%$ if PCGs are added. Therefore, we can conclude that including chronic conditions implied by prescribed drugs roughly doubles the predictive performance and hence it is certainly a preferred option. The results are quite consistent across individual years; the small differences can be explained by the relatively small sample. Additionally, as our sample is getting older, the increased predictive performance of the PCG model can be attributed to higher prevalence of chronic conditions which are characterised by predictable costs. Thirdly, drug prescription patterns change in time and it is possible that the practice in 2003 and 2004 matches better the classification used. The implication of this argument is that drug classification used for a PCG model should be updated regularly if it is to be used in practice.

Table 3

Overall Performance of Different Models Using $\mathbf{R}^{2}$ and Prediction Ratios (actual / predicted expenditures)

\begin{tabular}{|l|l|c|c|c|c|c|c|c|c|c|c|c|}
\hline \multirow{2}{*}{} & \multicolumn{9}{|c|}{ Prediction indices for each decile } & $\begin{array}{c}\text { Adjusted } \\
\mathbf{R}^{2}\end{array}$ \\
\cline { 3 - 13 } & $\mathbf{0 - 1 0 \%}$ & $\mathbf{1 0 - 2 0} \%$ & $\mathbf{2 0 - 3 0 \%}$ & $\mathbf{3 0 - 4 0 \%}$ & $\mathbf{4 0 - 5 0 \%}$ & $\mathbf{5 0 - 6 0} \%$ & $\mathbf{6 0 - 7 0 \%}$ & $\mathbf{7 0 - 8 0 \%}$ & $\mathbf{8 0 - 9 0 \%}$ & $\mathbf{9 0 - 1 0 0 \%}$ & \\
\hline $\mathbf{2 0 0 0}$ & no model & 0.123 & 0.203 & 0.270 & 0.343 & 0.432 & 0.544 & 0.698 & 0.945 & 1.449 & 4.965 & $0.0 \%$ \\
\hline $\mathbf{2 0 0 1}$ & no model & 0.113 & 0.195 & 0.262 & 0.337 & 0.425 & 0.537 & 0.699 & 0.959 & 1.474 & 4.956 & $0.0 \%$ \\
\hline $\mathbf{2 0 0 2}$ & no model & 0.111 & 0.194 & 0.262 & 0.336 & 0.425 & 0.537 & 0.702 & 0.964 & 1.483 & 4.942 & $0.0 \%$ \\
\hline $\mathbf{2 0 0 3}$ & no model & 0.105 & 0.181 & 0.246 & 0.316 & 0.401 & 0.513 & 0.674 & 0.935 & 1.454 & 5.137 & $0.0 \%$ \\
\hline $\mathbf{2 0 0 4}$ & no model & 0.100 & 0.173 & 0.237 & 0.308 & 0.396 & 0.512 & 0.679 & 0.946 & 1.464 & 5.080 & $0.0 \%$ \\
\hline $\mathbf{2 0 0 0}$ & demo & 0.185 & 0.295 & 0.385 & 0.477 & 0.569 & 0.678 & 0.836 & 1.043 & 1.432 & 4.275 & $3.6 \%$ \\
\hline $\mathbf{2 0 0 1}$ & demo & 0.172 & 0.289 & 0.381 & 0.474 & 0.576 & 0.686 & 0.850 & 1.064 & 1.455 & 4.125 & $4.4 \%$ \\
\hline $\mathbf{2 0 0 2}$ & demo & 0.169 & 0.289 & 0.379 & 0.477 & 0.579 & 0.693 & 0.844 & 1.059 & 1.458 & 4.107 & $4.4 \%$ \\
\hline $\mathbf{2 0 0 3}$ & demo & 0.166 & 0.273 & 0.365 & 0.456 & 0.547 & 0.674 & 0.823 & 1.028 & 1.439 & 4.307 & $3.2 \%$ \\
\hline $\mathbf{2 0 0 4}$ & demo & 0.167 & 0.279 & 0.370 & 0.465 & 0.565 & 0.685 & 0.838 & 1.058 & 1.452 & 4.288 & $4.3 \%$ \\
\hline $\mathbf{2 0 0 1}$ & PCG & 0.190 & 0.314 & 0.413 & 0.511 & 0.620 & 0.735 & 0.904 & 1.125 & 1.489 & 3.738 & $8.5 \%$ \\
\hline $\mathbf{2 0 0 2}$ & PCG & 0.191 & 0.321 & 0.417 & 0.523 & 0.633 & 0.754 & 0.911 & 1.129 & 1.489 & 3.724 & $8.2 \%$ \\
\hline $\mathbf{2 0 0 3}$ & PCG & 0.193 & 0.309 & 0.408 & 0.507 & 0.606 & 0.742 & 0.894 & 1.108 & 1.476 & 3.924 & $8.9 \%$ \\
\hline $\mathbf{2 0 0 4}$ & PCG & 0.186 & 0.309 & 0.408 & 0.511 & 0.622 & 0.749 & 0.909 & 1.121 & 1.483 & 3.838 & $9.5 \%$ \\
\hline
\end{tabular}

A similar conclusion may be drawn from the prediction ratios. PCG models attain ratios closer to one (where the predicted costs equal the actual expenditures) contrasted to the situation of the demographic model or no model at all. Better performance of the models with PCGs is noticeable especially for the last decile. Adding PCGs thus enables to explain some of expenditures of high-cost patients. However, there 
are two notable exceptions - the eight and the ninth decile. For both of these deciles PCG models underpredict actual costs and they are consistently worse than both the demographic model and the no model case. This indicates that chronic conditions concentrated in these deciles incur higher actual costs than the costs implied by the regression coefficients of PCG models. The consistency across years points to a systematic pattern and a need to further refinement of the PCG classification.

The next table (Table 4) brings different expected costs for different models. The index one is set for costs of girls aged 15-19. For a demographic model alone, the cost indices range from 0.67 (men 20-24) to 4.91 (women 75-79), more than a sevenfold difference. If a PCG model is applied, the indices for younger groups without a chronic condition are basically the same as in the demographic model since young people have a chronic condition only very rarely. The indices for older groups are lower than before, implying a shift of predicted costs from age to PCG risk factors.

For a low-cost chronic condition such as hypertension-low, a difference between demographic and the PCG model is not significant for older groups because such condition is frequent at this age and it does not incur extra additional costs. For younger groups, even this condition is exceptional and the PCG model enables to adequately compensate for it. For a very costly chronic condition such as Diabetes type I (people taking insulin) the expected costs and hence indices are much higher for all age groups. In addition, by using PCGs, the difference between the lowest-cost group (0.66) and the highest (9.06) is much higher. This shows the ability of PCG models to discriminate between different health conditions within each of the age/gender group.

Table 4

Indices for Expected Costs Based on Different Models (2004)

\begin{tabular}{|c|c|c|c|c|c|c|c|c|c|c|c|c|c|c|c|c|c|c|}
\hline \multicolumn{19}{|c|}{ Demographic model } \\
\hline & $0-4$ & $5-9$ & $\begin{array}{l}10- \\
14\end{array}$ & $\begin{array}{l}15- \\
19\end{array}$ & $\begin{array}{l}20- \\
24\end{array}$ & $\begin{array}{l}25- \\
29\end{array}$ & $\begin{array}{l}30- \\
34\end{array}$ & $\begin{array}{l}35- \\
39\end{array}$ & $\begin{array}{l}40- \\
44\end{array}$ & $\begin{array}{l}45- \\
49\end{array}$ & $\begin{array}{l}50- \\
54\end{array}$ & $\begin{array}{c}55- \\
59\end{array}$ & $\begin{array}{l}60- \\
64\end{array}$ & $\begin{array}{l}65- \\
69\end{array}$ & $\begin{array}{l}70- \\
74\end{array}$ & $\begin{array}{l}75- \\
79\end{array}$ & $\begin{array}{l}80- \\
84\end{array}$ & 85- \\
\hline M & 1.47 & 1.10 & 0.89 & 0.72 & 0.67 & 0.90 & 0.84 & 1.06 & 1.09 & 1.50 & 1.81 & 2.67 & 2.99 & 3.47 & 4.91 & 4.71 & 4.71 & 4.15 \\
\hline $\mathbf{F}$ & 1.26 & 1.01 & 0.94 & 1.00 & 1.03 & 1.33 & 1.30 & 1.33 & 1.54 & 1.97 & 2.09 & 2.35 & 2.93 & 3.54 & 3.94 & 4.98 & 4.19 & 4.48 \\
\hline \multicolumn{19}{|c|}{ Demo + PCG model - no PCG } \\
\hline M & 1.46 & 1.05 & 0.88 & 0.71 & 0.66 & 0.83 & 0.78 & 0.96 & 0.98 & 1.29 & 1.54 & 2.18 & 2.33 & 2.63 & 3.76 & 3.25 & 3.31 & 2.65 \\
\hline $\mathbf{F}$ & 1.27 & 1.00 & 0.91 & 1.00 & 1.02 & 1.30 & 1.27 & 1.26 & 1.44 & 1.79 & 1.80 & 1.89 & 2.29 & 2.54 & 2.56 & 3.56 & 2.55 & 2.80 \\
\hline \multicolumn{19}{|c|}{ Demo + PCG model - hypertension-low } \\
\hline M & 2.36 & 1.95 & 1.78 & 1.61 & 1.56 & 1.74 & 1.68 & 1.86 & 1.88 & 2.20 & 2.45 & 3.08 & 3.23 & 3.53 & 4.66 & 4.15 & 4.21 & 3.55 \\
\hline $\mathbf{F}$ & 2.17 & 1.90 & 1.81 & 1.90 & 1.92 & 2.20 & 2.17 & 2.16 & 2.34 & 2.69 & 2.70 & 2.79 & 3.19 & 3.44 & 3.46 & 4.46 & 3.45 & 3.70 \\
\hline \multicolumn{19}{|c|}{ Demo + PCG model - Diabetes type I } \\
\hline M & 6.76 & 6.35 & 6.17 & 6.01 & 5.95 & 6.13 & 6.07 & 6.26 & 6.27 & 6.59 & 6.8 & 7.48 & 7.63 & 7.93 & 9.06 & 8.55 & 8.61 & 7.95 \\
\hline $\mathrm{F}$ & 6.57 & 6.30 & 6.21 & 6.30 & 6.32 & 6.60 & 6.57 & 6.55 & 6.74 & 7.09 & 7.0 & 7.19 & 7.59 & 7.84 & 7.86 & 8.86 & 7.84 & 8.10 \\
\hline
\end{tabular}

\subsection{Quantitative Significance}

We have shown that PCGs considerably increase predictive performance of the demographic model. In this section we would like to add more details to the quantitative significance of this improvement. In this short scrutiny we are limited by the fact that 
we do not know actual distribution of people classed into chronic conditions for all sickness funds operating in the Czech Republic so we cannot provide an exact figure as to the amount of money that will be distributed differently if a PCG risk adjustment model is implemented. However, we can still make informative conclusions based on current experience with the demographic risk adjustment and statistics from the regressions.

Table 5

Quantitative Impact Measures of Different Risk Factors

\begin{tabular}{|l|r|r|r|r|r|}
\hline & $\mathbf{2 0 0 0}$ & \multicolumn{1}{|c|}{$\mathbf{2 0 0 1}$} & \multicolumn{1}{c|}{$\mathbf{2 0 0 2}$} & \multicolumn{1}{c|}{$\mathbf{2 0 0 3}$} & \multicolumn{1}{c|}{$\mathbf{2 0 0 4}$} \\
\hline Root mean square error (no model) / mean & $275.8 \%$ & $268.2 \%$ & $270.3 \%$ & $313.6 \%$ & $280.7 \%$ \\
\hline Sum of squares of errors (demo / no model) & $3.7 \%$ & $4.5 \%$ & $4.4 \%$ & $3.3 \%$ & $4.3 \%$ \\
\hline Sum of squares of errors (PCG / no model) & n.a. & $8.6 \%$ & $8.3 \%$ & $9.0 \%$ & $9.5 \%$ \\
\hline Mean absolute error (no model) / mean & $88.0 \%$ & $88.8 \%$ & $89.3 \%$ & $91.8 \%$ & $91.2 \%$ \\
\hline Sum of absolute errors (demo / no model) & $45.1 \%$ & $47.7 \%$ & $48.7 \%$ & $47.3 \%$ & $49.9 \%$ \\
\hline Sum of absolute errors (PCG / no model) & n.a. & $54.5 \%$ & $56.6 \%$ & $56.4 \%$ & $57.5 \%$ \\
\hline
\end{tabular}

Table 5 shows regression statistics for years 2000-2004. The first and the fourth row provide information on how dispersed from a mean the data are. Root mean square error is a quadratic score which gives higher weight (penalty) to high deviations from the mean and hence not surprisingly the figures for all years are very high, almost three times the mean in each year. Mean absolute error, on the contrary, is a linear measure assigning equal weight to each deviation. Both measures indicate high dispersion of health care data and hence potentially high weight to be placed on the risk factors if they are able to explain it. The second and the third row give percentage of variance measured by sum of square errors that is explained by demographic and PCG models, respectively. This is equivalent to the definition of R2. The figures are almost identical to the adjusted R2 already presented; the PCG models are about twice successful compared to the demographic models. Finally, the fifth and the sixth row provide the proportion of explained sum of absolute errors. Based on these measures, the explanatory power of both models is higher as no extra penalty for inability to explain high costs is incurred, but the difference between demographic and PCG models is not so pronounced as in the case of the quadratic score. This confirms the conclusion drawn from the prediction ratios that the most significant comparative advantage of PCGs is their ability to explain some of very high costs. This is a very plausible property as the high costs patients are the most prone to risk selection.

\section{Policy Recommendations}

In this section we discuss various policy issues associated with risk adjustment and risk selection. Based on the lessons learned in other countries we analyse the situation in the Czech Republic and attempt to draw relevant policy conclusions. In our analysis we focus primarily on the trends to introduce managed competition in the Czech Republic. We start with the country comparison presented in the Table 6. 
As argued by van de Ven (2007) the potential profits from risk selection depend also on the types and costs of care for which the insurers bear financial responsibility. In the table it can be seen that in the Czech Republic the insurers are held responsible for all types of listed care except for sick leave payments. This creates ample room for risk selection. Particularly, the inclusion of home health care, nursing home care and psychiatric care which are characterised by a small group of users with (very) high costs and utilisation that is highly predictable creates significant potential profits from risk selection. Therefore, a relevant policy recommendation would be to give special attention and make different financing arrangements for these types of care to mitigate the problem of risk selection.

Table 6

Types of Care for Which Sickness Funds Bear Financial Responsibility (based on van de Ven, 2007)

\begin{tabular}{|l|c|c|c|c|c|c|}
\hline & Belgium & Germany & Israel & Netherlands & Switzerland & $\begin{array}{c}\text { Czech } \\
\text { Republic }\end{array}$ \\
\hline $\begin{array}{l}\text { Physicians } \\
\text { services }\end{array}$ & Yes & Yes & Yes & Yes & Yes & Yes \\
\hline Hospital care & Yes & Yes & Yes & Yes & Yes & Yes \\
\hline $\begin{array}{l}\text { Financial } \\
\text { responsibility for } \\
\text { hospital's capital } \\
\text { costs }\end{array}$ & $0 \%$ & $0 \%$ & $100 \%$ & $5 \%$ & $100 \%$ & $100 \%$ \\
\hline Prescription drugs & Yes & Yes & Yes & Yes & Yes & Yes \\
\hline Physiotherapy & Restricted & Yes & Restricted & Restricted & Yes & Yes \\
\hline Dental care & Restricted & Yes & Restricted & Restricted & No & Yes \\
\hline Home health care & Yes & Restricted & Restricted & No & Yes & Yes \\
\hline Nursing home care & Yes & No & No & No & Yes & Yes \\
\hline Psychiatric care & Yes(a) & Yes & No & No & Restricted & Yes \\
\hline $\begin{array}{l}\text { Sick leave } \\
\text { payments }\end{array}$ & No & Yes(b) & No & No & No & No \\
\hline
\end{tabular}

a With large co-payments by consumers.

${ }^{\mathrm{b}} \mathrm{About} 7 \%$ of total expenditures of the mandatory sickness fund insurance.

Secondly, the potential profits from risk selection depend also on the proportion of health care costs for which an insurer is accountable for. If a high fraction of actual health care costs is reimbursed retrospectively or financed from other sources than the insurance premiums, the risk that the insurer bears is lowered and hence also the incentives for risk selection and vice versa. In the Czech Republic, the risk-sharing arrangement is the only explicit mechanism that decreases the financial risk of the insurers after they receive prospectively set risk-adjusted payments. Based on this arrangement, the insurers are reimbursed $80 \%$ costs above a threshold which is set to equal thirty times the average health care costs for an average enrolee. High level of financial accountability of insurers creates motivation for risk selection and hence it asks for improvement in the risk adjustment system. 
Experience from other countries particularly from Switzerland (Paolucci, 2007) demonstrates that supplemental voluntary health insurance is a powerful tool for risk selection. Unlike mandatory health insurance where refusing enrolees based on health status is typically prohibited, selling voluntary health insurance allows to screen health status of potential enrolees and to reject those who would be unprofitable for the mandatory insurance if both types of insurance are sold by the same entities. Currently, the basic benefit package is very broad in the Czech Republic and it leaves little room for voluntary health insurance. However, proposed plans of some health policy makers to reduce the benefit package and to introduce supplemental health insurance would mean a significant thread of risk selection if this measure is not accompanied by a corresponding improvement in the risk adjustment system.

Furthermore, as we already discussed, entrance of new insurers will increase competition in the Czech health insurance market. If the risk adjustment does not keep pace with this trend, the situation can easily create early winners - the insurers who will benefit from the imperfect system and who will block the attempts for further improvement (Hellman, 1998). In Switzerland the lobbying of the risk selecting fund against the risk adjustment improvement was so evident that newspapers published the names of the members of parliament who were paid by this fund (van de Ven, 2007). As the Czech Republic is still a young democracy with lower adherence to formal and informal rules, occurrence of such situations is easily imaginable.

Lessons from Israel point to a problem of risk selection if insurers are allowed to provide services directly to consumers. Implicit selection activities include waiting times for particular specialities, accessibility problems to certain clinics or opening of clinics where there is mainly young and healthy population (van de Ven, 2007). On the other hand, the Netherlands is much more cautious to allow so far only a limited vertical integration of insurers and providers. Insurers are allowed to set up new pharmacies or outpatient primary care centres. The natural policy recommendation would again be the improvement of the risk adjustment system to mitigate motivation for risk selection. Additionally, a tight regulation of the health care market (such as monitoring and enforcing accessibility of particular specialties) is necessary if a vertical integration of insurers and health care providers is allowed.

Other tools of managing health care system by insurers such as selective contracting and freely negotiated prices between insurers and providers, high-deductible or managed care plans are the last point we would like to discuss in this section. These tools can help to contain health care costs but increase the risk selection problem. The conclusion of this point and the whole section is hence straightforward; the freedom (more tools for managing a health care system by insurers) must be associated with accountability (a better risk adjustment system and tighter regulation of a health care market).

\section{Conclusion}

In this paper we have discussed various methods to improve the risk-adjustment system in the Czech Republic. We have concluded that using pharmaceutical cost groups (PCGs) are a feasible option and verified on a sample of data that models with PCGs have about a twofold better performance measured by R2 compared to 
the demographic model, consistent with the results encountered in the literature. We have also shown that the results are quantitatively important seeing the amount of financial resources that are being redistributed based on PCGs. We have also shown than the chronic conditions are quite homogenous and we hypothesise that costs of individual chronic conditions are likely to converge if the health care market in the Czech Republic becomes more competitive and the insurers have stronger incentives to contain costs. However, we want to emphasise that the PCG classification we used in this paper is a good starting point, but it must be fine-tuned to account for new drug molecules and medical practice if it is to be used in the current practice.

We also analysed the Czech health care market. The current status quo is likely to change due to reform proposals of the policy makers. The insurers will receive more tools to manage provision of health care services, such as split between mandatory and voluntary health insurance, selective contracting, freely negotiated prices of health care services or high deductible and manage care health plans. Furthermore, entrance of new insurers is expected, which will make the system more competitive and possibly more profit oriented. Although these changes aim to achieve higher level of production efficiency of the health care system, the experience from other countries show that they can be associated with a negative effect of risk selection if they are not accompanied by a tight regulation, specifically by a more sophisticated risk adjustment system. The imperfect risk adjustment system could easily produce early winners, the situation in which the insurers who would benefit from partial reform would block later attempts to improve the system.

\section{References}

Clark, D. O., von Korff, M., Sauders, K., Baluch, W. M., Simon, G. E. (1995), "A Chronic Disease Score with Empirically Derived Weights." Medical Care, 33 (8), pp. 783-795.

Ellis, R. P. (2008), "Risk Adjustment in Health Care Markets: Concepts and Applications." in Lu, M., Jonnson, E., eds., Paying for Health Care: New Ideas for a Changing Society. Weinheim: Wiley-VCH Publishers, pp. 177-222.

Enthoven, A. C. (1988), Theory and Practice of Managed Competition in Health Care Finance. Amsterdam: North Holland.

Enthoven, A. C. (1993), "The History and Principles of Managed Competition." Health Affairs, Supplement 1, 12, pp. 24-48.

Enthoven, A. C., van de Ven W. P. M. M. (2007), "Going Dutch - Managed-Competition Health Insurance in the Netherlands." New England Journal of Medicine, 357 (24), pp. 2421-23.

Glied, S. A. (1999), "Managed Care." NBER Working Paper No. W7205.

Hellman, J. (1998), "Winners Take All: The Politics of Partial Reform in Postcommunist Transitions." World Politics, 50 (2), pp. 203-234.

Hroboň, P. (2007), "Kompenzace rizika jako podmínka smysluplné konkurence plátců v ČR." Presented at the 3rd Prague International Health Summit.

Lamers L. M. (1998), "Pharmacy Cost Groups: a Risk Adjuster for Capitation Payments Based on the Use of Prescribed Drugs?" Institute of Health Policy and Management, Erasmus University.

Lamers, L. M., van Vliet, R. C. J. A. (2003), "Health-based Risk Adjustment: Improving the Pharmacy-Based Cost Group Model to Reduce Gaming Possibilities." European Journal of Health Economics, 4 (2), pp. 107-114. 
Lamers, L.M., van Vliet, R.C.J.A. (2004), "The Pharmacy-based Cost Group Model: Validating and Adjusting the Classification of Medications for Chronic Conditions to the Dutch Situation." Health Policy, 68 (1), pp. 113-121.

Paolucci, F., Schut, E., Beck, K., Greß, S., van de Voorde, C., Zmora, I. (2007), "Supplementary Health Insurance as a Tool for Risk Selection in Mandatory Basic Health Insurance Markets." Health Economics, Policy and Law, 2 (2), pp. 173-192.

ÚZIS (2004), Zdravotnická ročenka ČR 2004. Praha: Ústav zdravotnických informací a statistiky České republiky.

Van de Ven, W. P. M. M., Ellis, E. P. (2000): "Risk Adjustment in Competitive Health Plan Markets." in Culyer, A.J., Newhouse, J.P., eds., Handbook of Health Economics, Amsterdam: North Holland, pp. 755-845.

Van de Ven W. P. M. M., Beck, K., Buchner, F., Chernichovsky, D., Gardiol, L., Holly, A., Lamers, L. M., Schokkaert, E., Shmueli, A., Spycher, S., van de Voorde, C., van Vliet, R. C., Wasem, J., Zmora, I. (2003), "Risk Adjustment and Risk Selection on the Sickness Fund Insurance Market in Five European Countries." Health Policy, 65 (1), pp. 75-98.

Van de Ven W. P. M. M., Beck, K., van de Voorde, C., Wasem, J., Zmora, I. (2007), "Risk Adjustment and Risk Selection in Europe: 6 Years Later." Health Policy, 83 (2-3), pp. 162-179. Van Vliet, R. C. J. A. (2007), "Berekening normbedragen risicovereveningsmodel." College voor zorgverzekeringen. 